\title{
Trends in hospitalisation rates for road traffic injuries in child motor vehicle passengers in New South Wales, July 1998 - June 2005
}

\author{
Wei Du, Caroline F Finch, Andrew Hayen and Julie Hatfield
}

In n New South Wales, being a motor vehicle passenger has consistently been one of the leading causes of fatal injury for children aged under 17 years since 1996. ${ }^{1}$ Between 2000 and 2005, the child road death rate declined by $4.5 \%$ per annum in Australia, ${ }^{2}$ possibly due to road safety initiatives such as road condition improvements, enforcement of restraint use, and public education campaigns, as well as improved trauma care services. ${ }^{3}$

However, life-saving preventive measures may result in fewer deaths at the expense of an increase in serious non-fatal injuries, ${ }^{4}$ which may in turn lead to long-term disability for patients and a burden on health care systems. In Australia, about a thousand child passengers (aged 0-16 years) were seriously injured due to road crashes per annum between July 1999 and June 2002. ${ }^{5}$

Overall gains made in safety for child motor vehicle passengers should therefore be evaluated in terms of serious injuries as well as deaths. Knowledge of such injuries is needed to set prevention strategies and priorities. ${ }^{6}$ Here, we examine trends in hospitalisation rates for injuries due to traffic crashes among NSW-resident child motor vehicle passengers (aged 0-15 years) by analysing population-based hospitalisation data.

\section{METHODS}

\section{Data sources}

The NSW Inpatient Statistics Collection (ISC) is a financial year-based census of hospital separations maintained by NSW Health. It covers all public and private hospitals in NSW and also includes complete records of NSW residents who were admitted to public hospitals outside NSW up to the 2003-04 financial year. ${ }^{7}$ The reason for hospital admission is coded at the time of separation according to the 10th revision of the International Classification of Diseases, Australian Modification (ICD-10-AM). ${ }^{8}$ There were four editions of the ICD-10-AM during the study period, but with no major changes to how road crashes and injury were coded across editions. We extracted

\section{ABSTRACT}

Objective: To analyse changes in the incidence of injuries requiring hospitalisation for child passengers in motor vehicle crashes.

Design, setting and participants: Population-based study of children (aged 0-15 years) residing in New South Wales and admitted to hospital for injuries resulting from a traffic crash in the period 1 July 1998 - 30 June 2005, identified from the NSW Inpatient Statistics Collection.

Main outcome measures: Age-standardised rates of hospitalisation for injuries, and trends by inpatient demographics, severity of injuries, and injury sites and types.

Results: 2297 children were hospitalised for injuries sustained in a motor vehicle crash over the study period. The overall hospitalisation rate for injuries was relatively constant, with a non-significant decline of $-0.4 \%(95 \% \mathrm{Cl},-3.1 \%$ to $2.3 \%)$. The rate of hospitalisation for serious injuries also declined non-significantly $(-5.5 \%[95 \% \mathrm{Cl}$, $-11.8 \%$ to $1.1 \%])$. Only hospitalisation rates for traumatic brain injuries declined significantly $(-11.1 \%[95 \% \mathrm{Cl},-19.0 \%$ to $-2.8 \%])$ over the study period.

Conclusion: The rate of hospitalisation for injuries to NSW-resident child motor vehicle passengers due to traffic crashes has not significantly decreased. High hospitalisation rates and the subsequent burden to the community and public health system make further injury prevention efforts for child motor vehicle passengers a priority.

MJA 2007; 187: 515-518

data from the ISC on inpatients' age, sex, medical diagnoses and external cause codes for the period 1 July 1998 - 30 June 2005.

Australian Bureau of Statistics censusbased single-year-of-age-, sex- and end-ofyear-specific population estimates in NSW were used as the rate denominators, and corresponding single-year-of-age-based Australian population figures for 2001 were used as the standard population for direct standardisation.

\section{Case selection}

We selected cases where child passengers of a motor vehicle of a car-based chassis design (eg, a car or utility truck) involved in a traffic crash were hospitalised. Study subjects were restricted to children aged 0-15 years (excluding fetal injury) resident in NSW, with a first external cause coded as V40.6-V48.6, V40.9-V48.9, V50.6-V58.6 or V50.9-V58.9 (ie, passengers), or V49.5, V49.6, V49.9, V59.5, V59.6 or V59.9 (ie, unspecified travel mode).

Being injured was defined as having any of the first 20 diagnosis fields coded in the ICD-10-AM range S00-S99, T00-T14,
T20-T31, T79 or T89. ${ }^{8}$ We excluded episodes of care that were identified as readmissions to either the same or another hospital within 28 days (Box 1). Patients who died during the episode of care were included in the study, while those who died before admission to hospital were excluded.

\section{Injury types and severity}

Injuries were grouped by severity, body region, type and number (single or multiple). To represent injury severity, we applied the ICD-10-AM diagnosis-based Injury Severity Score (ICISS), which is an estimate of the probability of survival from a given injury (lower scores represent more severe injuries). ${ }^{9}$ For each patient, we selected the lowest ICISS score (ie, the worst injury) across all injury diagnoses to represent overall injury severity. ${ }^{10}$ Patients with a minimum ICISS score of $\leqslant 0.941$ were defined as being "seriously" injured, because these patients will almost always be admitted to hospital. ${ }^{11}$

\section{Statistical analysis}

SAS version 9.1 (SAS Institute, Cary, NC, USA) was used to perform all data analyses. 
Directly standardised rates, expressed per 100000 person-years for NSW-resident children aged $\leqslant 15$ years, were calculated to allow for changes in the age and sex structure of the population over time. Trends in age-adjusted rates were assessed using the per cent change annualised estimator (PCAE), which is robust regardless of whether or not the annual change in rate is linear. $^{12}$ The PCAE-associated $P$ values were used to test whether or not there was an amount of per cent change in rate during a period. ${ }^{12}$ A $P$ value $<0.05$ was considered statistically significant. Children were grouped by ages corresponding to recommendations for child restraint systems: 0-4 years (child restraints); 5-8 years (booster seats); 9-12 years (potential extension of booster seat use); and 13-15 years (adult seatbelts).

\section{RESULTS}

A total of 2297 children aged 0-15 years were hospitalised for injuries sustained in a traffic crash as a passenger in a car $(n=$ $2252 ; 98 \%)$ or utility truck ( $n=45 ; 2 \%)$ (Box 2). Of these, 213 children (9\%) had an unspecified travel mode. Fifteen children $(0.7 \%)$ died during the episode of care.

Overall, the hospitalisation rate for children with injuries changed slightly, but not significantly, by $-0.4 \%$ (95\% CI, $-3.1 \%$ to $2.3 \%$ ) over the study period (Box 3). The hospitalisation rate for children with serious injuries changed non-significantly by $-5.5 \%$ (95\% CI, $-11.8 \%$ to $1.1 \%$ ), compared with a non-significant $0.7 \%$ change $(95 \% \mathrm{CI},-0.8 \%$ to $2.2 \%$ ) in hospitalisation for children with less serious injuries.

Among different injury types, only traumatic brain injuries demonstrated a significant reduction in hospitalisation rate over the study period, with a change of $-11.1 \%$ (95\% CI, $-19.0 \%$ to $-2.8 \%$ ) (Box 3 ). Hospitalisation rates associated with fractures, internal organ injuries and spinal injuries all showed a non-significant decline over the study period.

\section{DISCUSSION}

We found no significant overall reduction in the rate of hospitalisation among NSWresident children (aged $0-15$ years) for injuries sustained as a motor vehicle passenger in a traffic crash over a 7 -year period.
Although the overall annual rate of hospitalisation for injuries remained constant over the study period, our findings suggest a greater reduction in serious injuries (ICISS $\leqslant 0.941$ ) than less serious injuries (ICISS $>0.941$ ). This is perhaps not surprising, as most interventions have been designed with the ultimate aim of preventing loss of life. Children with less serious injuries comprised the largest group, and their hospitalisation rate showed a non-significant increase over time. In contrast, the hospitalisation rate for children with serious injuries or injuries of possible high severity, such as fractures, internal organ injuries, and spinal injuries, had a steady but non-significant decline over time, consistent with previous findings of the reduction in road deaths of children in Australia. ${ }^{2}$

Only hospitalisation rates for traumatic
1 Selection of child motor vehicle passengers (aged 0-15 years) hospitalised due to a road traffic crash

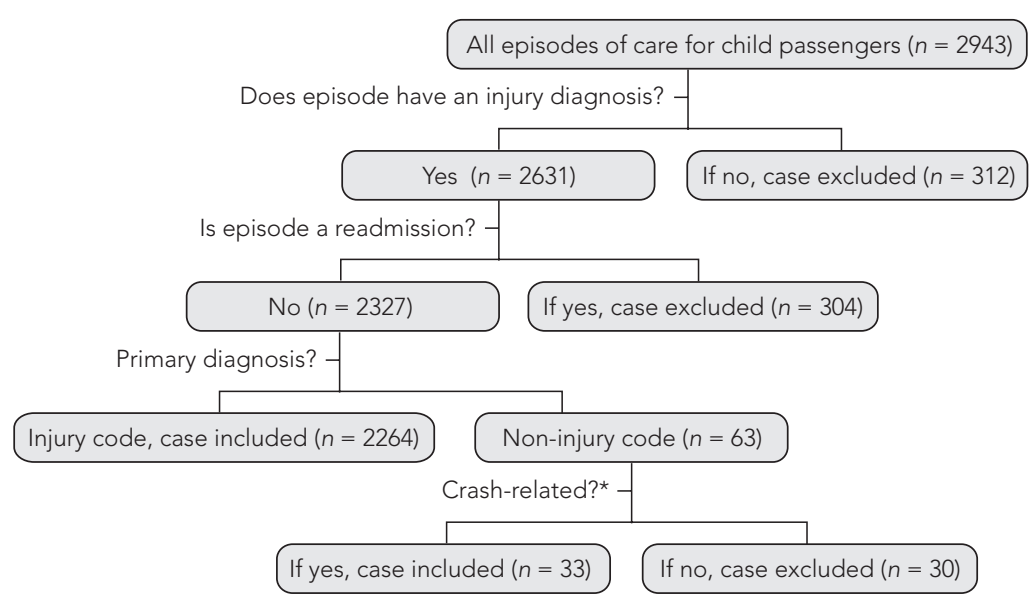

*We excluded episodes that were for rehabilitation or medical follow-up and those with a primary diagnosis such as infection. We included episodes with a primary diagnosis that was potentially crash-related, such as "acquired cerebral cysts" and "loss of teeth". brain injuries showed a significant decrease over time, reflecting either a real reduction in these injuries or changes in hospital admission practices for such cases. Between 1988 and 1998 in New Zealand, Stephenson and colleagues also found a substantial decrease in the hospitalisation rate for traumatic brain injuries and suggested that an improvement in diagnosis and treatment may have contributed in part to this decline. ${ }^{13}$ Durbin et al found a 59\% reduction in the risk of injury, including severe head or brain injuries, for child motor vehicle passengers aged 4-7 years using appropriate child

\section{Number (\%) of child motor vehicle passengers (aged 0-15 years) resident in New South Wales hospitalised for injuries in} each financial year, July 1998 - June 2005*

\begin{tabular}{|c|c|c|c|c|c|c|c|}
\hline & $1998-99$ & 1999-2000 & 2000-01 & $2001-02$ & 2002-03 & 2003-04 & 2004-05 \\
\hline \multicolumn{8}{|c|}{ Age group (years) } \\
\hline $0-4$ & 75 (25.2\%) & 78 (22.1\%) & 70 (20.5\%) & $68(20.1 \%)$ & 72 (22.0\%) & 75 (21.6\%) & $68(23.2 \%)$ \\
\hline $5-8$ & 71 (23.8\%) & 102 (28.9\%) & 80 (23.5\%) & $83(24.6 \%)$ & 72 (22.0\%) & 85 (24.5\%) & $61(20.8 \%)$ \\
\hline $9-12$ & $72(24.2 \%)$ & $76(21.5 \%)$ & $82(24.0 \%)$ & $83(24.6 \%)$ & 94 (28.7\%) & 78 (22.5\%) & $73(24.9 \%)$ \\
\hline $13-15$ & 80 (26.8\%) & 97 (27.5\%) & 109 (32.0\%) & 104 (30.8\%) & 89 (27.2\%) & 109 (31.4\%) & 91 (31.1\%) \\
\hline \multicolumn{8}{|l|}{ Sex } \\
\hline Boys & $124(41.6 \%)$ & 192 (54.4\%) & $174(51.0 \%)$ & $163(48.2 \%)$ & $157(48.0 \%)$ & $179(51.6 \%)$ & 130 (44.4\%) \\
\hline Girls & 174 (58.4\%) & $161(45.6 \%)$ & 167 (49.0\%) & 175 (51.8\%) & $170(52.0 \%)$ & 168 (48.4\%) & $163(55.6 \%)$ \\
\hline Total & 298 (100\%) & $353(100 \%)$ & 341 (100\%) & 338 (100\%) & 327 (100\%) & 347 (100\%) & $293(100 \%)$ \\
\hline
\end{tabular}

* Of the total 2297 children, 15 died during the episode of care in hospital. 
restraints in 15 states of the United States. ${ }^{14}$ We did not have information on restraint use in our sample so cannot say whether it may have contributed to our findings, nor whether the admission pattern for traumatic brain injury reflects the real incidence in the population of interest. Future research should link hospital data with crash data, to allow an examination of crash severity and restraint use.

Although the ISC hospital data provided extensive details of injury diagnoses, which may contribute to developing injury prevention strategies, the lack of causal data, such as crash severity and use of protective devices, limited our ability to test whether there have been shifts from serious to less serious injuries, or shifts between injury types. For example, the use of child restraint systems may protect a child passenger from death or from suffering severe thorax injuries, while increasing the likelihood of abdominal injuries. ${ }^{15}$

Other limitations of analysing hospital datasets include multiple counting of the same injuries, and ambiguity caused by cases in which the child's mode of travel in the car is unspecified, which in some cases may mean that the child was driving illegally rather than being a passenger. Although we had used an internally linked dataset to define criteria for subject selection, these limitations may affect the hospitalisation rates we found.

Injuries to child motor vehicle passengers in NSW result in many hospitalisations each year and remain a significant public health issue. Further efforts to reduce child road

3 Age-standardised hospitalisation rates per 100000 person-years for injured child motor vehicle passengers (aged 0-15 years) resident in New South Wales, and trends in rates by inpatient demographics and injury types, * July 1998 - June 2005

Rate per 100000 person-years

\begin{tabular}{|c|c|c|c|c|c|c|c|c|c|}
\hline & No. & 1998-99 & $1999-2000$ & $2000-01$ & $2001-02$ & $2002-03$ & $2003-04$ & $2004-05$ & $\%$ change in rate $(95 \% \mathrm{Cl})^{\dagger}$ \\
\hline Total & 2297 & 21.15 & 24.92 & 23.95 & 23.69 & 22.96 & 24.43 & 20.59 & $-0.4 \%(-3.1 \%$ to $2.3 \%)$ \\
\hline \multicolumn{10}{|l|}{ Age group (years) } \\
\hline $0-4$ & 506 & 17.16 & 17.91 & 16.00 & 15.62 & 16.73 & 17.53 & 15.98 & $-1.2 \%(-6.7 \%$ to $4.6 \%)$ \\
\hline $5-8$ & 554 & 19.69 & 28.23 & 22.09 & 22.99 & 20.15 & 24.11 & 17.33 & $-2.1 \%(-7.8 \%$ to $3.9 \%)$ \\
\hline $9-12$ & 558 & 20.41 & 21.25 & 22.56 & 22.58 & 25.57 & 21.35 & 19.99 & $-0.3 \%(-5.8 \%$ to $5.5 \%)$ \\
\hline $13-15$ & 679 & 30.35 & 36.52 & 40.75 & 38.78 & 32.97 & 39.85 & 32.93 & $1.4 \%(-3.8 \%$ to $6.8 \%)$ \\
\hline \multicolumn{10}{|l|}{ Sex } \\
\hline Boys & 1119 & 17.20 & 26.39 & 23.85 & 22.28 & 21.48 & 24.56 & 17.83 & $0.6 \%(-3.6 \%$ to $5.0 \%)$ \\
\hline Girls & 1178 & 25.30 & 23.38 & 24.06 & 25.17 & 24.52 & 24.31 & 23.49 & $-1.2 \%(-4.8 \%$ to $2.5 \%)$ \\
\hline \multicolumn{10}{|l|}{ Severity of injury } \\
\hline Less serious & 1886 & 16.80 & 19.91 & 19.10 & 20.67 & 19.17 & 19.57 & 17.50 & $0.7 \%(-0.8 \%$ to $2.2 \%)$ \\
\hline Serious ${ }^{\ddagger}$ & 411 & 4.35 & 5.01 & 4.85 & 3.02 & 3.79 & 4.86 & 3.09 & $-5.5 \%(-11.8 \%$ to $1.1 \%)$ \\
\hline \multicolumn{10}{|l|}{ Number of injuries } \\
\hline Single & 1060 & 9.32 & 12.42 & 10.30 & 9.60 & 10.39 & 12.54 & 9.98 & $1.1 \%(-3.2 \%$ to $5.7 \%)$ \\
\hline Multiple & 1237 & 11.83 & 12.50 & 13.65 & 14.09 & 12.57 & 11.89 & 10.61 & $-1.8 \%(-5.4 \%$ to $2.0 \%)$ \\
\hline \multicolumn{10}{|l|}{ Injured body regions ${ }^{\S}$} \\
\hline Isolated & 1379 & 13.02 & 16.08 & 13.38 & 13.25 & 13.62 & 15.64 & 12.03 & $-1.3 \%(-4.1 \%$ to $1.6 \%)$ \\
\hline Multiple & 884 & 8.07 & 8.50 & 10.15 & 10.09 & 9.06 & 8.44 & 7.99 & $-0.2 \%(-4.6 \%$ to $4.4 \%)$ \\
\hline \multicolumn{10}{|l|}{ Body region } \\
\hline Head & 1138 & 11.10 & 13.43 & 12.40 & 11.95 & 10.88 & 11.21 & 9.02 & $-3.4 \%(-7.2 \%$ to $0.5 \%)$ \\
\hline Abdomen & 727 & 6.84 & 7.87 & 7.95 & 7.15 & 6.61 & 7.89 & 6.95 & $0.3 \%(-4.5 \%$ to $5.3 \%)$ \\
\hline Extremity & 556 & 5.07 & 5.11 & 6.43 & 6.05 & 5.34 & 5.76 & 5.47 & $1.3 \%(-4.2 \%$ to $7.1 \%)$ \\
\hline Neck & 338 & 2.21 & 3.12 & 3.58 & 3.85 & 3.93 & 3.65 & 3.43 & $7.6 \%(-0.5 \%$ to $16.7 \%)$ \\
\hline Thorax & 317 & 3.23 & 2.70 & 3.04 & 3.09 & 3.58 & 3.66 & 3.08 & $-0.8 \%(-7.8 \%$ to $6.7 \%)$ \\
\hline Shoulder & 275 & 2.86 & 2.34 & 2.75 & 2.96 & 3.09 & 2.89 & 2.52 & $-2.1 \%(-9.6 \%$ to $6.0 \%)$ \\
\hline Hip and thigh & 177 & 1.77 & 2.62 & 1.56 & 2.10 & 1.62 & 1.76 & 1.05 & $-8.3 \%$ ( $-18.6 \%$ to $2.7 \%)$ \\
\hline Other" & 176 & 1.64 & 1.62 & 1.83 & 1.47 & 1.69 & 1.97 & 2.18 & $4.9 \%(-4.7 \%$ to $15.6 \%)$ \\
\hline \multicolumn{10}{|l|}{ Specific injury type } \\
\hline Fractures & 691 & 6.36 & 8.20 & 7.47 & 7.73 & 6.82 & 6.90 & 5.27 & $-3.1 \%(-8.1 \%$ to $2.2 \%)$ \\
\hline Internal organ injuries & 477 & 4.77 & 5.65 & 5.82 & 4.14 & 4.29 & 5.21 & 3.73 & $-4.0 \%$ ( $-9.9 \%$ to $2.2 \%)$ \\
\hline $\begin{array}{l}\text { Traumatic brain } \\
\text { injuries }\end{array}$ & 290 & 3.13 & 3.95 & 3.71 & 2.46 & 2.88 & 2.75 & 1.55 & $-11.1 \%(-19.0 \%$ to $-2.8 \%)$ \\
\hline Spinal injuries & 173 & 1.79 & 1.57 & 1.97 & 1.69 & 1.97 & 1.82 & 1.40 & $-4.0 \%(-13.8 \%$ to $6.6 \%)$ \\
\hline
\end{tabular}

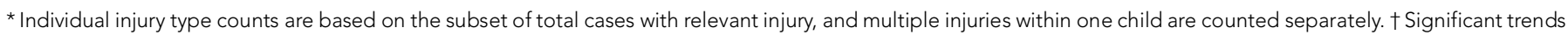

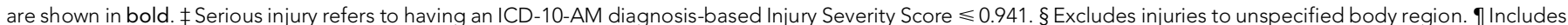
injuries to unspecified body region. 
trauma are warranted. Future studies using crash scene data (eg, use of child restraint system, seating position) or investigation of road safety beliefs and behaviour of parent or caregiver drivers can further explore the relative effectiveness of current injury countermeasures relevant to child road trauma.

\section{ACKNOWLEDGEMENTS}

Wei Du is supported by an APAI PhD scholarship from the Australian Research Council. Caroline Finch is supported by a National Health and Medical Research Council (NHMRC) Principal Research Fellowship. Andrew Hayen is supported by the NSW Injury Risk Management Research Centre, with core funding provided by the NSW Health Department, the NSW Roads and Traffic Authority and the Motor Accidents Authority. Julie Hatfield is supported by the Injury, Trauma and Rehabilitation NHMRC Capacity Building Grant in Population Health.

We wish to thank the Centre for Epidemiology and Research at NSW Health for providing data from the Health Outcomes and Information Statistical Toolkit (HOIST).

\section{COMPETING INTERESTS}

None identified.

\section{AUTHOR DETAILS}

Wei Du, MPH, PhD Student ${ }^{1}$

Caroline F Finch, PhD, NHMRC Principal

Research Fellow ${ }^{2}$

Andrew Hayen, PhD, Research Fellow ${ }^{1}$

Julie Hatfield, PhD, Senior Research Fellow ${ }^{1}$
1 NSW Injury Risk Management Research Centre, University of New South Wales, Sydney, NSW.

2 School of Human Movement and Sport Sciences, University of Ballarat, Ballarat, VIC.

Correspondence: w.du@unsw.edu.au

\section{REFERENCES}

1 NSW Child Death Review Team. Annual Report 2004. Sydney: NSW Commission for Children and Young People, 2005.

2 Australian Transport Safety Bureau. Road deaths Australia, 2005 statistical summary. Canberra: ATSB, 2005.

3 Australian Transport Council. National Road Safety Strategy 2001-2010. Canberra: ATC, 2000.

4 Finch CF, Hayen A. Governmental health agencies need to assume leadership in injury prevention [editorial]. Inj Prev 2006; 12: 2-3.

5 Australian Transport Safety Bureau. Road safety statistics report. Serious injury due to road crashes. Canberra: ATSB, 2004.

6 Injury Surveillance Workgroup, State and Territorial Injury Prevention Directors Association. Consensus recommendations for using hospital discharge data for injury surveillance. Marietta, Ga: STIPDA, 2003.

7 Epidemiology and Surveillance Branch, NSW Department of Health. Health Outcomes Information and Statistical Toolkit (HOIST). http:// hoist.health.nsw.gov.au (internal access only) (accessed Jun 2006).

8 National Centre for Classification in Health. International statistical classification of diseases and related health problems, 10th revision,
Australian modification. Vol. 1. Tabular list of diseases. Sydney: National Centre for Classification in Health, 2000.

9 Stephenson S, Henley G, Harrison JE, Langley JD. Diagnosis based injury severity scaling: investigation of a method using Australian and New Zealand hospitalisations. Inj Prev 2004; 10: 379-383.

10 Kilgo PD, Osler TM, Meredith W. The worst injury predicts mortality outcome the best: rethinking the role of multiple injuries in trauma outcome scoring. J Trauma 2003; 55: 599-606.

11 Cryer C, Langley J, Davie G. A critical look at some IClSS-based indicators of serious injury incidence. The 6th International Conference on Measuring the Burden of Injury; 2006 Apr 1; Durban, South Africa; 2006.

12 Fay MP, Tiwari RC, Feuer EJ, Zou Z. Estimating average annual percent change for disease rates without assuming constant change. Biometrics 2006; 62: 847-854.

13 Stephenson S, Langley J, Cryer C. Effects of service delivery versus changes in incidence on trends in injury: a demonstration using hospitalised traumatic brain injury. Accid Anal Prev 2005; 37: 825-832.

14 Durbin DR, Elliott MR, Winston FK. Belt-positioning booster seats and reduction in risk of injury among children in vehicle crashes. JAMA 2003; 289: 2835-2840.

15 Javouhey E, Guérin AC, Gadegbeku B, et al. Are restrained children under 15 years of age in cars as effectively protected as adults? Arch Dis Child 2006; 91: 304-308.

(Received 29 Mar 2007, accepted 16 Aug 2007) 